\title{
A Whole Blood Thrombus Mimic: Constitutive Behavior Under Simple Shear
}

\author{
Gabriella P. Sugerman ${ }^{a}$, Sotirios Kakaletsis ${ }^{b}$, Parin Thakkar ${ }^{a}$, Armaan Chokshi ${ }^{a}$, Sapun H. Parekh \\ and Manuel K. Rausch ${ }^{a, b, g, *}$
}

${ }^{a}$ University of Texas at Austin, Department of Biomedical Engineering, 107 W Dean Keeton St, Austin, TX 78712
${ }^{b}$ University of Texas at Austin, Department of Aerospace Engineering \& Engineering Mechanics, 2617 Wichita St, Austin, TX 78712
${ }^{g}$ University of Texas at Austin, Oden Institute for Computational Engineering and Sciences, 201 E 24th St, Austin, TX 78712

\section{ARTICLE INFO}

\section{Keywords:}

venous thrombus

hyperelasticity

large deformation

deep vein thrombosis

pulmonary embolism

\begin{abstract}
A B S TR ACT
Deep vein thrombosis and pulmonary embolism affect 300,000-600,000 patients each year in the US. The progression from deep vein thrombus to pulmonary embolism occurs when blood clots, as a whole or partially, break off from the deep veins and eventually occlude the pulmonary arteries. Venous thromboembolism is the cause of up to 100,000 deaths per year in the US alone. To date, we don't fully understand this mechanical process among other reasons because in-vivo samples are difficult to obtain, highly heterogeneous, and their shapes are inappropriate for most mechanical tests. Toward overcoming these obstacles, we have set out to develop an in-vitro thrombus mimic and to test this mimic under large deformation simple shear. In addition to reporting on the mechanics of our mimics under simple shear, we explore the sensitivity of their mechanics to coagulation conditions and blood storage time, and compare three hyperelastic material models for their ability to fit our data. We found that thrombus mimics made from whole blood demonstrate strain-stiffening, a negative Poynting effect, and hysteresis when tested quasi-statically to $50 \%$ strain under simple shear. Additionally, we found that the stiffness of these mimics does not significantly vary with coagulation conditions or blood storage times. Of the three hyperelastic constitutive models that we tested, the Ogden model provided the best fits to both shear stress and normal stress. In conclusion, we developed a robust protocol to generate regularly-shaped, homogeneous thrombus mimics that lend themselves to simple shear testing under large deformation. Future studies will extend our model to include the effect of maturation and explore its fracture properties toward a better understanding of embolization.
\end{abstract}

\section{Introduction}

Deep vein thrombosis and pulmonary embolism affect 300,000-600,000 patients each year in the US alone (Cushman, 2007). Collectively known as venous thromboembolism, these disorders are characterized by pathologic blood coagulation restricting or eliminating blood flow through the veins (Kearon, 2003). The initial thrombus is subject to a variety of possible outcomes: it may resolve with relatively few symptoms (Dewyer et al., 2007; Nguyen et al., 2015), persist and reduce blood flow causing post-thrombotic syndrome (Ashrani and Heit, 2009), or break apart and shed emboli into the bloodstream, which in turn may result in obstruction of flow to critical organs, such as the lung (van Langevelde et al., 2013). The latter outcome is the most catastrophic leading to approximately 100,000 deaths every year in the US alone according to the CDC (Beckman et al., 2010). The deformation, fracture, and eventual embolization of thrombus are inherently mechanical processes (Basmadjian, 1989; Johnson et al., 2017). Thus, the mechanics of thrombus, and venous thrombus in particular, has been of immense interest.

Investigations of thrombus mechanics have taken many forms. Because fibrin is the primary structural constituent of early thrombi, there has been intense effort invested in

\footnotetext{
*Corresponding author

@manuel.rausch@utexas.edu (M.K. Rausch)

- www. manuelrausch.com (M.K. Rausch)
}

studying and characterizing the mechanics of fibrin networks (Piechocka et al., 2010; Brown et al., 2009; Liu et al., 2006; Fleissner et al., 2016). However, in reality, thrombi are composed of not only fibrin, but also so called formed elements, platelets and red blood cells. Thus, other studies have also considered the role of cellularity in thrombus mechanics (Gersh et al., 2009; Kim et al., 2017). These studies have found that closely-packed elements significantly alter the mechanical behavior of thrombus (Tutwiler et al., 2018; van Oosten et al., 2019) requiring a holistic approach toward studying thrombus. Additionally, the constitution and thus mechanics of in-vivo thrombi are not time-invariant (Rausch and Humphrey, 2017). For example, we have previously probed the uniaxial tensile behavior of venous thrombi developed in mice at two time points: after two weeks and after four weeks of formation (Lee et al., 2015). Additionally, we characterize the thrombi's constitution via histology. We found that thrombus "maturation" (i.e., resident time in-vivo) profoundly influenced the compositional and mechanical properties of the explanted thrombi. Hence, to develop a fundamental understanding for venous thrombus mechanics we must consider thrombi in their full complexity as well as across time scales. While animal models for deep vein thrombus can be useful tools, as shown in our previous study, they provide significant challenges in addition to costing animal lives. For example, thrombus maturation is not a homogeneous process. We found that thrombi are invaded with immune and synthetic cells that begin converting the ini- 
bioRxiv preprint doi: https://doi.org/10.1101/2020.07.19.210732; this version posted July 19, 2020. The copyright holder for this preprint (which was not certified by peer review) is the author/funder, who has granted bioRxiv a license to display the preprint in perpetuity. It is made available under aCC-BY-ND 4.0 International license.

Mechanics of a Whole Blood Thrombus Mimic
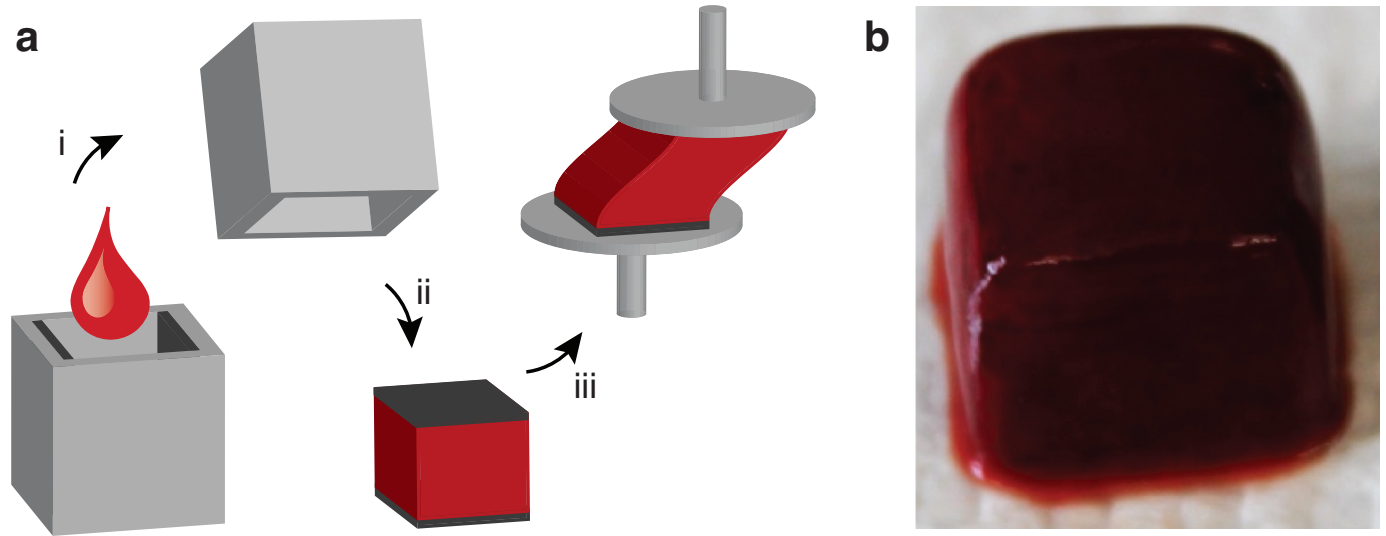

Figure 1: Generation of thrombus mimics. (a) (i) We mixed anticoagulated whole bovine blood with calcium chloride and coagulated both in cube-shaped molds lined on two opposing sides with hook-and-loop fabric. (ii) After coagulation, we removed samples with integrated hook-and-loop fabric from molds. (iii) We secured the mimics to pin stubs with a drop of super glue on the back of the hook-and-loop fabric. (b) Exemplary thrombus mimic (shown without hook-and-loop fabric to illustrate sample quality.)

tial fibrin-based thrombus into a collageneous pseudo-tissue from the radial boundary inward. The arising spatial heterogeneity of thrombus renders these tissue complex model systems. Additionally, in-vivo thrombus are not regularlyshaped and make testing via standard methods difficult.

To study the mechanics of venous thrombus while overcoming the shortcomings of in-vivo studies, we aim to develop an in-vitro model of evolving venous thrombus. In our current work, we established the methodology for generating venous thrombus mimics based on fresh coagulated blood and investigated their baseline mechanical behavior. To this end, we developed a simple shear testing protocol, applied our test protocol to thrombus mimics made from bovine blood, and reported the material parameters for three hyperelastic material models. Additionally, we tested the sensitivity of these mimics' mechanics to coagulation conditions. Specifically, we varied both the amount of calcium chloride used to reverse our anticoagulant and the coagulation time on the shear deformation behavior, and report on the effect of blood storage time.

\section{Methods}

\subsection{Thrombus mimic generation}

We generated thombi from bovine blood (Lampire Biological Laboratories, PA, USA) that was collected with CPDA1 anticoagulant at $14 \%$ volume:volume and stored at $4{ }^{\circ} \mathrm{C}$ for 12-72 hours prior to experimentation. We initiated coagulation by adding calcium chloride to a final concentration of 10, 20, or $40 \mathrm{mM}$ (Roessler et al., 2014; Kim et al., 2017). During coagulation, we gently mixed blood with a wide-mouth pipette, and then injected it into $12 \times 10 \times 10 \mathrm{~mm}$ cube molds lined on two opposing sides with hook-and-loop fabric such that the cube volume was $1000 \mathrm{~mm}^{3}$, see Figure 1a. Samples coagulated for $60 \mathrm{~min}, 90 \mathrm{~min}$, or $120 \mathrm{~min}$ at $37^{\circ} \mathrm{C}$ before we removed them from the mold, see Figure $1 \mathrm{~b}$. We defined the start of coagulation time when calcium chloride was added, while we defined the end of coagulation time when shear testing experiments commenced.

\subsection{Shear testing}

Following the specified coagulation time, we removed samples from their molds and secured the hook-and-loop fabric-covered ends to pin stubs via super glue. Note, the super glue bonded the smooth surfaces of the hook-and-loop fabric to the pin stub. In other words, the super glue did not contact the thrombus material at any point. We let the glue dry for one minute before we submerged the samples in phosphate-buffered saline (PBS) at $37^{\circ} \mathrm{C} \pm 2$. Throughout testing, we maintained sample temperature by circulating attemperature PBS through our bath.

We conducted simple shear experiments by symmetrically displacing the top plate of our custom simple shear testing device by $\pm 5 \mathrm{~mm}$ in each direction at a rate of $0.1 \mathrm{~mm} / \mathrm{s}$ for ten consecutive cycles. Simultaneously, we measured force in three directions using a $2 \mathrm{~N}$ capacity triaxial load cell. With a custom LabView program, we collected time, displacement, and force in shear and normal directions during testing.

\subsection{Inverse Analysis}

Simple shear is not so simple (Destrade et al., 2012). It is well-known that non-zero tractions on the incline surface may be required to maintain a homogeneous deformation field during simple shear experiments (Horgan and Murphy, 2011). Given that simple shear testing apparati maintain traction free conditions on the incline surface, homogeneous solutions to simple shear are likely inaccurate. Schmid et al. have previously demonstrated the need for inverse finite element analysis to extract material parameters for soft tissue from simple shear experiments (Schmid et al., 2008). Thus, we too developed an (iterative) inverse finite element analysis framework using Matlab R2019a and FEBio 2.9.1 to identify the material parameters for our thrombus mimics (Maas et al., 2012). 
bioRxiv preprint doi: https://doi.org/10.1101/2020.07.19.210732; this version posted July 19, 2020. The copyright holder for this preprint (which was not certified by peer review) is the author/funder, who has granted bioRxiv a license to display the preprint in perpetuity. It is made available under aCC-BY-ND 4.0 International license.

Mechanics of a Whole Blood Thrombus Mimic

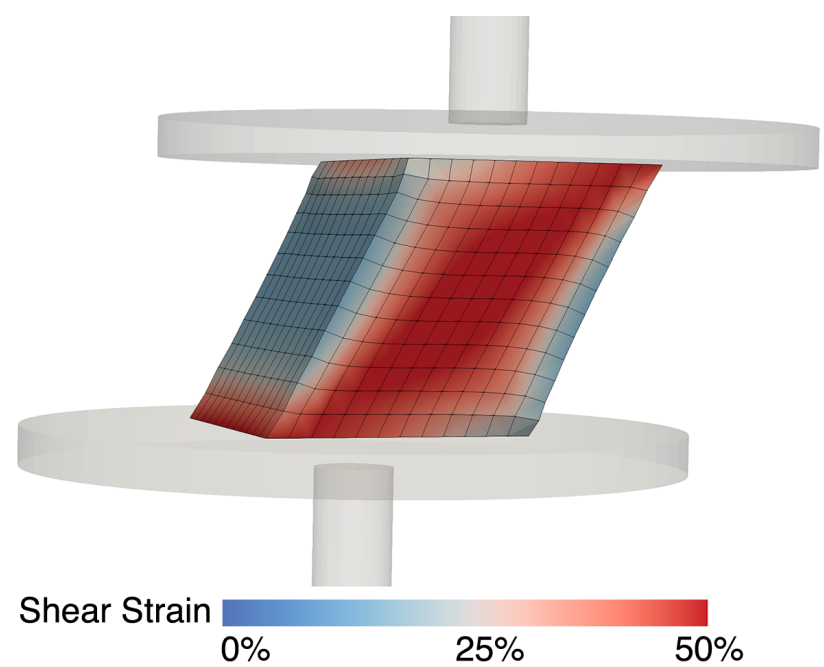

Figure 2: Simple shear is not so simple. Locally resolved GreenLagrange shear strain $\gamma=2 E_{x z}$ derived from our inverse finite element simulation, where $E_{x z}$ is the off-diagonal shear element of the Green-Lagrange strain tensor.

Specifically, for the forward simulations, we modeled each sample as a cube with $10 \mathrm{~mm}$ edge length discretized by an equal number of linear hexahedral mixed elements along each edge. We defined the boundary conditions by fixing displacements of the sample's bottom surface, while attaching the top surface nodes to a rigid body. In turn, we constrained the rigid body to displace in only the shear direction. During the simulation, we applied the experimental pin stub displacement profile to the rigid body, while measuring its reaction forces to the deforming sample. See Figure 2 for a sample simulation which depicts the highly heterogeneous deformation field under simple shear.

For the constitutive fitting, we tested three hyperelastic material models, assumed to be nearly incompressible. To this end, we made use of the decoupled material formulation in FEBio that decomposes the deformation gradient $\mathbf{F}$ with the invariant $\boldsymbol{J}=\operatorname{det}(\mathbf{F})$ into an isochoric and volumetric part, i.e., $\tilde{\mathbf{F}}=J^{-1 / 3} \mathbf{F}$ and $J^{1 / 3} \mathbf{I}$, respectively. Accordingly, the deviatoric right Cauchy-Green tensor reads $\tilde{\mathbf{C}}=$ $\tilde{\mathbf{F}}^{T} \tilde{\mathbf{F}}$, while the deviatoric principal stretches read $\tilde{\lambda}_{i}$ and the first deviatoric invariant becomes $\tilde{I}_{1}=\operatorname{tr} \tilde{\mathbf{C}}$ (Holzapfel, 2000). Furthermore, $U(J)$ is the volumetric component of the strain energy, for which FEBio assumes the form $U(J)=$ $\frac{1}{2} K(\ln J)^{2}$ with bulk modulus $K$. Specifically, we identified the parameters to the following models:

1. Ogden model (Ogden, 1973)

$$
W(\mathbf{C})=\frac{c_{1}}{c_{2}^{2}}\left(\tilde{\lambda}_{1}^{c_{2}}+\tilde{\lambda}_{2}^{c_{2}}+\tilde{\lambda}_{3}^{c_{2}}-3\right)+U(J)
$$

2. Isotropic Fung-type (Fung, 1967; Demiray, 1972; Holzapfe et al., 2000)

$$
W(\mathbf{C})=\frac{c_{1}}{2 c_{2}}\left(\exp \left[c_{2}\left(\tilde{I}_{1}-3\right)\right]-1\right)+U(J)
$$

3. Yeoh model (Yeoh, 1993)

$$
W(\mathbf{C})=\sum_{i=1}^{3} c_{i}\left(\tilde{I}_{1}-3\right)^{i}+U(J) .
$$

Following a convergence analysis for all three models on the peak tangent and normal force values, we performed all simulations using a $12^{3}$ - element cube. For all tested samples, we estimated the values of the parameter vector $\mathbf{c}$ using non-linear least squares regression in Matlab. To this end, we defined the objective function $Z(\mathbf{c})$ to be minimized as follows

$$
\min Z(\mathbf{c})=\sum_{i=x, z} \sum_{j=1}^{n}\left|f_{i}^{f e m}\left(\gamma_{j}, \mathbf{c}\right)-f_{i}^{e x p}\left(\gamma_{j}\right)\right|^{2}
$$

where $x$ and $z$ imply the shear and normal force, respectively, over $n=100$ shear strain points $\gamma_{j}$. Thus, we fitted both the shear force and the normal force simultaneously. Specifically, we used Matlab to call FEBio with an initial guess for the material model parameters, performed a forward simulation in FEBio, read the simulation-based output forces in Matlab, computed the error metric via above objective function, and repeated this process iteratively until reaching our error minimum. Finally, for the optimal set of parameters $\mathbf{c}^{*}$, we evaluated goodness of fit across samples by comparing the normalized mean-square error (NMSE)

$$
e\left(\mathbf{c}^{*}\right)_{N M S E}=1-\frac{Z\left(\mathbf{c}^{*}\right)}{\sum_{i=x, z} \sum_{j=1}^{n}\left|f_{i}^{\exp }\left(\gamma_{j}\right)-\bar{f}^{\exp }\right|^{2}}
$$

where $\bar{f}^{e x p}$ is the mean recorded force over all data points for both normal and shear forces.

\subsection{Histology}

We generated thrombus mimics specifically for histology using $20 \mathrm{mM}$ calcium chloride and a coagulation time of 60 minutes. We then fixed those samples in $10 \%$ neutral buffered formalin for 48 hours. Subsequently, we dehydrated the samples in ethanol, embedded them in paraffin, and sectioned them at $5 \mu \mathrm{m}$ thickness. Following standard protocols, we stained all slides with hematoxylin and eosin (H\&E) to show red and white blood cells. We acquired histological images at 4, 10, 20 and 40× magnification with a BX53 (Olympus, Tokyo, Japan) microscope and an DP80 camera (Olympus, Tokyo, Japan) using bright-field imaging.

\subsection{Cell Counting}

We monitored viability of red blood cells and platelets by isolating and counting cells from blood stored for 1,2 , and 3 days. To this end, we centrifuged blood for 30 minutes at $200 \times \mathrm{g}$ to separate platelet-rich plasma (PRP) from red blood cells. We mixed PRP with an equal volume of HEPES buffer (140 mM NaCl, $2.7 \mathrm{mM} \mathrm{KCl}, 3.8 \mathrm{mM}$ HEPES, $5 \mathrm{mM}$ EGTA, in ultra-pure water) with prostaglandin E1 ( $1 \mu \mathrm{M}$ final concentration) then centrifuged the solution for 15 minutes at $100 \times \mathrm{g}$ to pellet contaminating cells and transferring PRP to 
bioRxiv preprint doi: https://doi.org/10.1101/2020.07.19.210732; this version posted July 19, 2020. The copyright holder for this preprint (which was not certified by peer review) is the author/funder, who has granted bioRxiv a license to display the preprint in perpetuity. It is made available under aCC-BY-ND 4.0 International license.

Mechanics of a Whole Blood Thrombus Mimic

a new tube. Finally, we centrifuged the PRP once more at $800 \times \mathrm{g}$ to pellet platelets which we subsequently washed in EDTA buffer $(10 \mathrm{mM}$ sodium citrate, $150 \mathrm{mM} \mathrm{NaCl}, 1 \mathrm{mM}$ EDTA, $1 \%$ (w/v) dextrose) and resuspended in modified Tyrode's buffer (Tyrode's (HIMEDIA), $5 \mathrm{mM}$ dextrose, $3 \mathrm{mg} / \mathrm{mL}$ bovine serum albumin, $1 \mu \mathrm{M}$ prostaglandin E1). Separately, we resuspended the red blood cell layer win $0.9 \% \mathrm{NaCl}$ (aqueous) and centrifuged it for 5 minutes at $500 \times \mathrm{g}$. We performed this step two additional times to wash and pack the red blood cells. Finally, we suspended the red blood cells in a storage buffer $(150 \mathrm{mM} \mathrm{NaCl}, 5 \mathrm{mM}$ dextrose, $3 \mathrm{mg} / \mathrm{mL}$ bovine serum albumin). Before counting red blood cells and platelets in a hemocytometer, we combined each solution of isolated cells with Trypan Blue $(0.4 \%$ aqueous $)$ in a $1: 4$ ratio.

\subsection{Statistical analysis}

We examined differences in toe-region stiffness and calfregion stiffness as functions of calcium chloride concentration and coagulation time using a Friedman test. Importantly, given our replicate number of three per group, our calf-stiffness correlation and variation, expectation of a large effect (Cohen's for-many-means-effect size of 0.4), and correction for the use of the Friedman test via its asymptotic relative efficiency, we reach a power 0.84 . We performed the actual power analysis in $\mathrm{G}^{*}$ Power (Version 3.1). Furthermore, we tested the time dependence of toe-region and calf-region stiffness as well as red blood cell and platelet count via least squares regression and Spearman correlation. We performed our statistical analyses in MATLAB R2019a. We considered results as significantly different for p-values smaller than 0.05. Throughout this text, we present data as mean \pm 1 standard deviation.

\section{Results}

Coagulation in molds yielded cubes of thrombus mimics which were ideal for histological analyses and simple shear experiments.

First, to illustrate the mimics' microstructure and composition, we stained samples via $H \& E$. Figure 3 shows $H \& E$ stains of a typical mimic at four magnification, from $4 \times$ to 40×. H\&E identifies white blood cell nuclei in dark purple and red blood cells in pink. Thus, it demonstrates the relative abundance of red blood cells compared to white blood cells. Under lower-magnification (i.e., $4 \times$ and $10 \times$ ) the sample appears mostly homogeneous with some areas of higher density, while higher-magnification images show cell-level inhomogeneity (i.e., $20 \times$ and $40 \times$ ). We interpret white space as areas of low cell density which are likely composed of fibrin network, as fibrin is not stained by H\&E. Note, samples did not demonstrate gradients in red blood cell density, which would indicate settling of cells during coagulation, as reported by others (Chernysh et al., 2020). Overall, our thrombus mimics appeared homogeneous without structural elements that would render it anisotropic.

Next, our primary goal was to investigate the constitutive behavior of our thrombus mimic via simple shear experiments. To this end, Figure 4 a depicts the shear stress of a representative mimic under simple shear. In complement, Figure $4 \mathrm{~b}$ shows the normal stress of the same sample. We found that samples under large deformation showed the classic "J-shaped" strain-stiffening behavior known from many other fibrous soft tissues (Rausch and Humphrey, 2016; Meador et al., 2020b,a). Samples also demonstrated some hysteresis, i.e., difference between loading and unloading. Interestingly, we found that our samples exhibited negative normal stress. In other words, when sheared our samples contracted rather than expanded, i.e., exhibited a negative Poynting effect (Mihai and Goriely, 2011; Janmey et al., 2007). In the subsequent text, when reporting on both shear stress and normal stress, we refer to the average (or midline) of the upstroke and downstroke, ignoring the material's viscoelasticity in a first approximation. Furthermore, to compare the mechanical behavior of thrombus mimics across various coagulation conditions, we extracted scalar metrics from these nonlinear stress-strain curves: first, we computed the tangent modulus at low strains (i.e., toe-stiffness). Second, we computed the tangent modulus at high strains (i.e., calf-stiffness), see Figure 4c. In summary, under simple shear our mimics exhibited a non-linear strain-stiffening response to shear while demonstrating a negative Poynting effect and hysteresis.

To explore the sensitivity of our thrombus mimics to coagulation conditions, we performed simple shear experiments on samples coagulated under various conditions. Figure 5 shows the average shear stress $( \pm 1$ standard deviation) across three samples for each coagulation time and calcium concentration. Qualitatively all curves look consistent across changes in calcium chloride concentration from 10 to $40 \mathrm{mM}$ and coagulation times from 60 to 120 minutes. We also quantitatively explored the sensitivity of our thrombus mimics to coagulation times and calcium chloride concentration by comparing toe- and calf-stiffness between samples. Figure 6a illustrates the insensitivity of toe-stiffness to changes of coagulation time or calcium chloride concentration (time: $p=0.6605$, concentration: $p=0.3292$ ). Similarly, Figure $6 \mathrm{~b}$ shows that clots with varying coagulation characteristics maintained similar stiffness in the calf region (time: $\mathrm{p}=0.2174$, concentration: $\mathrm{p}=0.3244$ ). Through qualitative and quantitative comparisons, we didn't find a significant effect of coagulation conditions.

Because we tested samples after 24 to 72 hours of storage (1-3 days), we were concerned that cell viability may affect our results. To this end, we report red blood cell and platelet count over time, see Figure 7a-b. Additionally, we compared shear stiffness metrics as a function of storage time, see Figure $7 \mathrm{c}-\mathrm{d}$. Least squares fits to all data declined marginally over three days, indicated by the negative R-values. However, none of the Spearman correlations were significant ( $p>0.05)$. Thus, it appears that storage times between 24 and 72 hours did not affect mechanical properties of our thrombus mimics.

Lastly, to identify the material parameters to our thrombus mimics, we fit our midline shear and normal force data using the Ogden, Yeoh, and Fung-type constitutive models. 
bioRxiv preprint doi: https://doi.org/10.1101/2020.07.19.210732; this version posted July 19, 2020. The copyright holder for this preprint (which was not certified by peer review) is the author/funder, who has granted bioRxiv a license to display the preprint in perpetuity. It is made available under aCC-BY-ND 4.0 International license.

Mechanics of a Whole Blood Thrombus Mimic
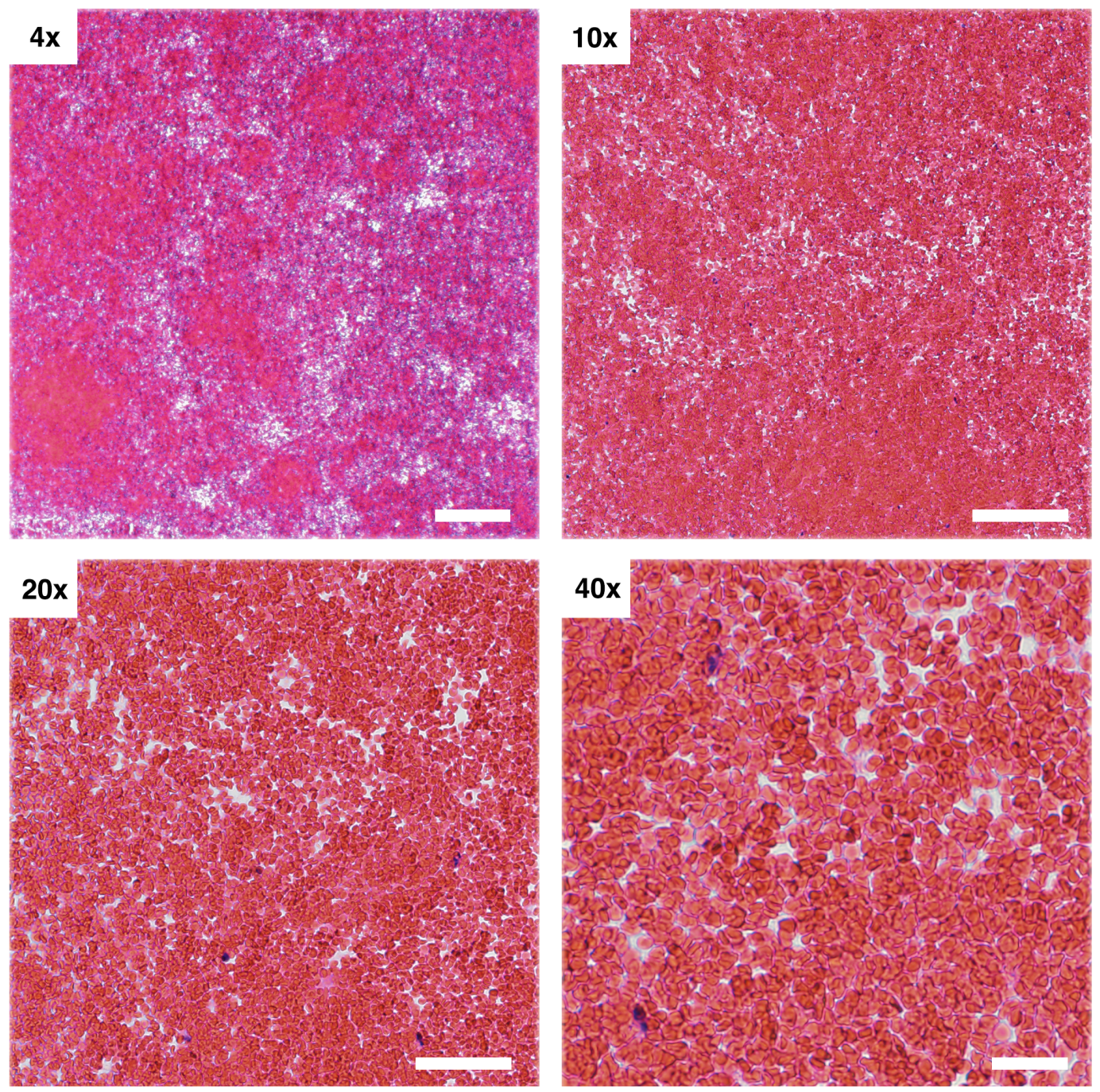

Figure 3: Thrombus mimics were predominantly homogeneous without a discernible density gradient. We took images of H\&E-

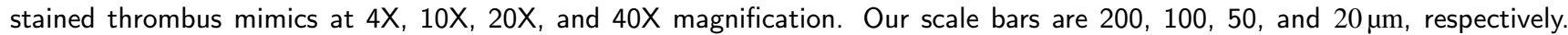
Lower-magnification images (i.e., 4X and 10X) appear mostly homogeneous with some areas of higher density, while highermagnification images show cell-level inhomogeneity (i.e., 20X and 40X). The shown thrombus mimic was coagulated with $20 \mathrm{mM}$ calcium chloride for $60 \mathrm{~min}$.

Figures 8a-c depict fits of all models to shear and normal stress for the same sample data set that was also depicted in Figure 4. The goodness-of-fit metric normalized meansquared error (NMSE) is inset in each subfigure. Note, a perfect fits yields a NMSE of 1 . Thus, the higher the NMSE the better the fit. See Table 1 for details on all tested samples, parameters, and goodness-of-fit data. Overall, of the three models the Ogden model fit both the shear data as well as the normal data qualitatively and quantitatively better than the other two models.

\section{Discussion}

\subsection{Summary}

We have successfully developed an in-vitro approach that yields regularly-shaped thrombus mimics that lend themselves well to simple shear testing under large deformation. This methodology is a first step on our path toward a robust in- vitro model for venous thrombus mechanics. In our thrombus mimics, we measured shear and normal stress and compared metrics of shear stiffness as a function of various coagulation conditions including calcium chloride concentration, coagulation times, and blood storage time.

\subsection{Why simple shear?}

We chose simple shear as the mode of deformation for two reasons: First, shear is likely thrombus' predominant in-vivo mode of deformation. Therefore, our testing modality reflects the natural mode of deformation most accurately. Second, simple shear is approximately volume preserving (Gardiner and Weiss, 2001). We believe that this minimizes the effects of intra-sample pressure gradients that lead to porous fluid flow and thus energy-dissipating momentum exchange between the fluid phase and the solid phase of the clearly poroelastic material (Suh and DiSilvestro, 1999). In turn, such theoretical decoupling reduces the overall viscoelas- 
bioRxiv preprint doi: https://doi.org/10.1101/2020.07.19.210732; this version posted July 19, 2020. The copyright holder for this preprint (which was not certified by peer review) is the author/funder, who has granted bioRxiv a license to display the preprint in perpetuity. It is made available under aCC-BY-ND 4.0 International license.

Mechanics of a Whole Blood Thrombus Mimic
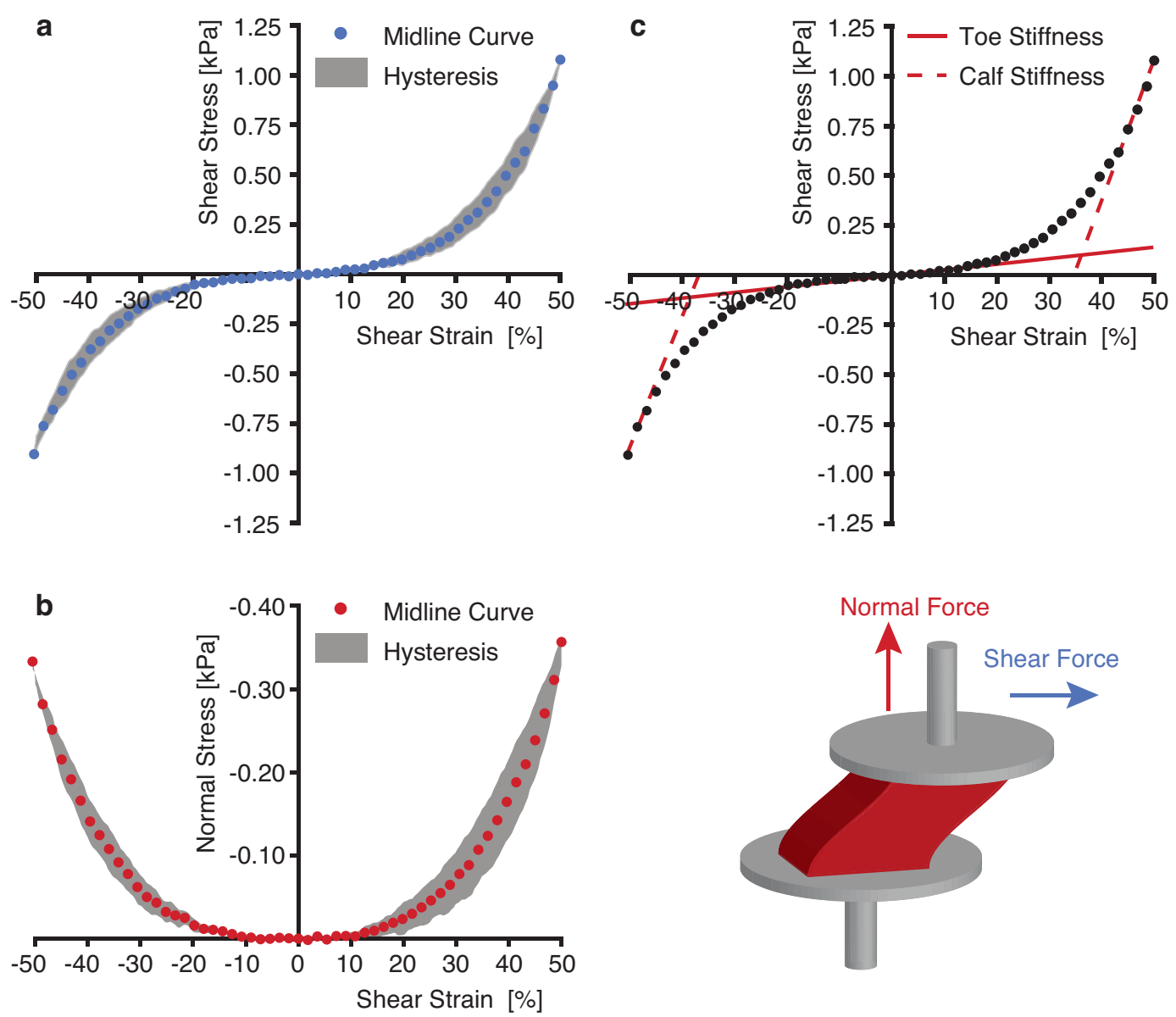

Figure 4: Thrombus mimics demonstrated shear-stiffening, negative normal stress, and hysteresis. Stress-strain behavior of a representative sample under simple shear: (a) Shear stress and (b) normal stress after nine preconditioning cycles. As a first approximation, we subsequently represent the mechanical behavior of our thrombus mimics by the average midline of the upstroke and downstroke (circles). (c) Depiction of tangent modulus at low strain (toe-stiffness) and at high strain (calf-stiffness). This representative thrombus mimic was coagulated with $20 \mathrm{mM}$ calcium chloride for $60 \mathrm{~min}$.
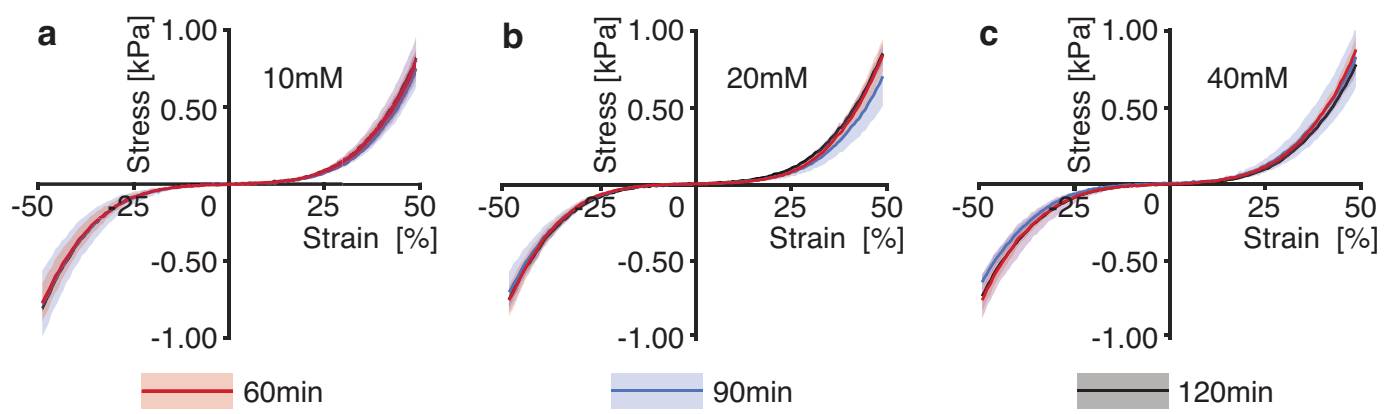

Figure 5: Shear stress appeared insensitive to changes in coagulation time or calcium chloride concentration. Mean and standard deviation of midline shear stress for samples coagulated for 60,90 , and 120 minutes with (a) $10 \mathrm{mM}$, (b) $20 \mathrm{mM}$, (c) $40 \mathrm{mM}$ calcium chloride. Each line represents an average across three samples.

tic phenomena and improves our approximation of mimic material as hyperelastic.

\subsection{Mechanics of our thrombus mimic}

Qualitatively, our mechanical testing via simple shear revealed a strain-stiffening material with negative Poynting effect and hysteresis. As to the strain-stiffening of thrombus, past reports have been mixed. While some studies showed that thrombus is strain-stiffening (Lee et al., 2015; Teng et al., 2015) others showed that it behaves linearly (Di Martino et al., 1998; Gasser et al., 2008; Geest et al., 2006). Disagreement between data likely stems from the drastic variation between samples due to differences in coagulation conditions (under flow versus stasis, on the arterial side ver- 
bioRxiv preprint doi: https://doi.org/10.1101/2020.07.19.210732; this version posted July 19, 2020. The copyright holder for this preprint (which was not certified by peer review) is the author/funder, who has granted bioRxiv a license to display the preprint in perpetuity. It is made available under aCC-BY-ND 4.0 International license.

Mechanics of a Whole Blood Thrombus Mimic
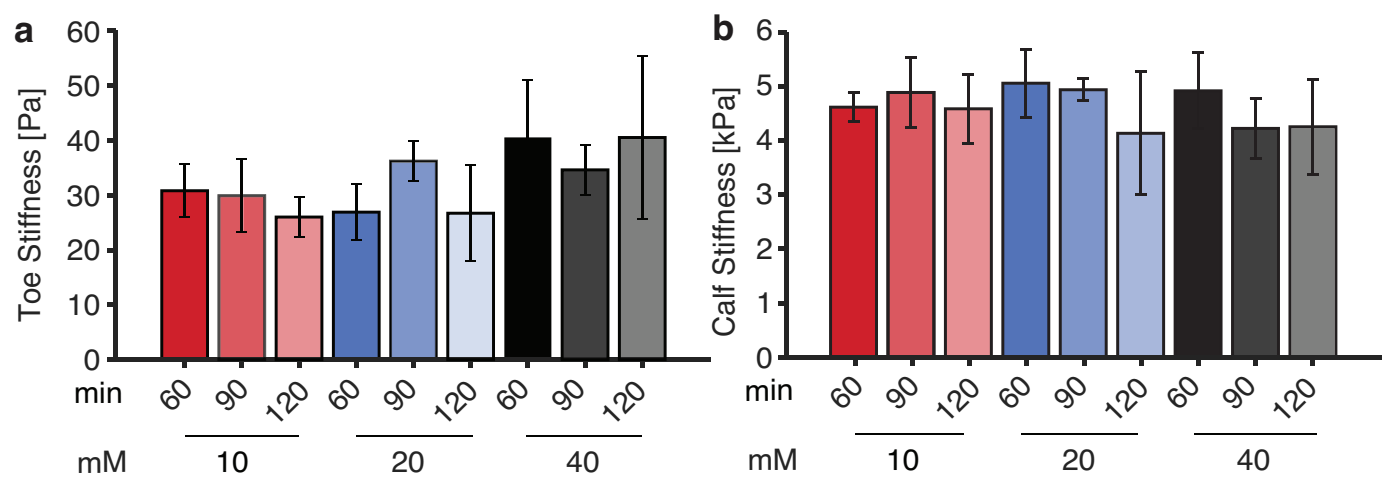

Figure 6: Thrombus mimic stiffness didn't appear to depend on calcium chloride concentration or coagulation time. Tangent stiffness computed at (a) low strain (toe-stiffness, $n=3$ per group), (b) high strain (calf-stiffness, $n=3$ per group).
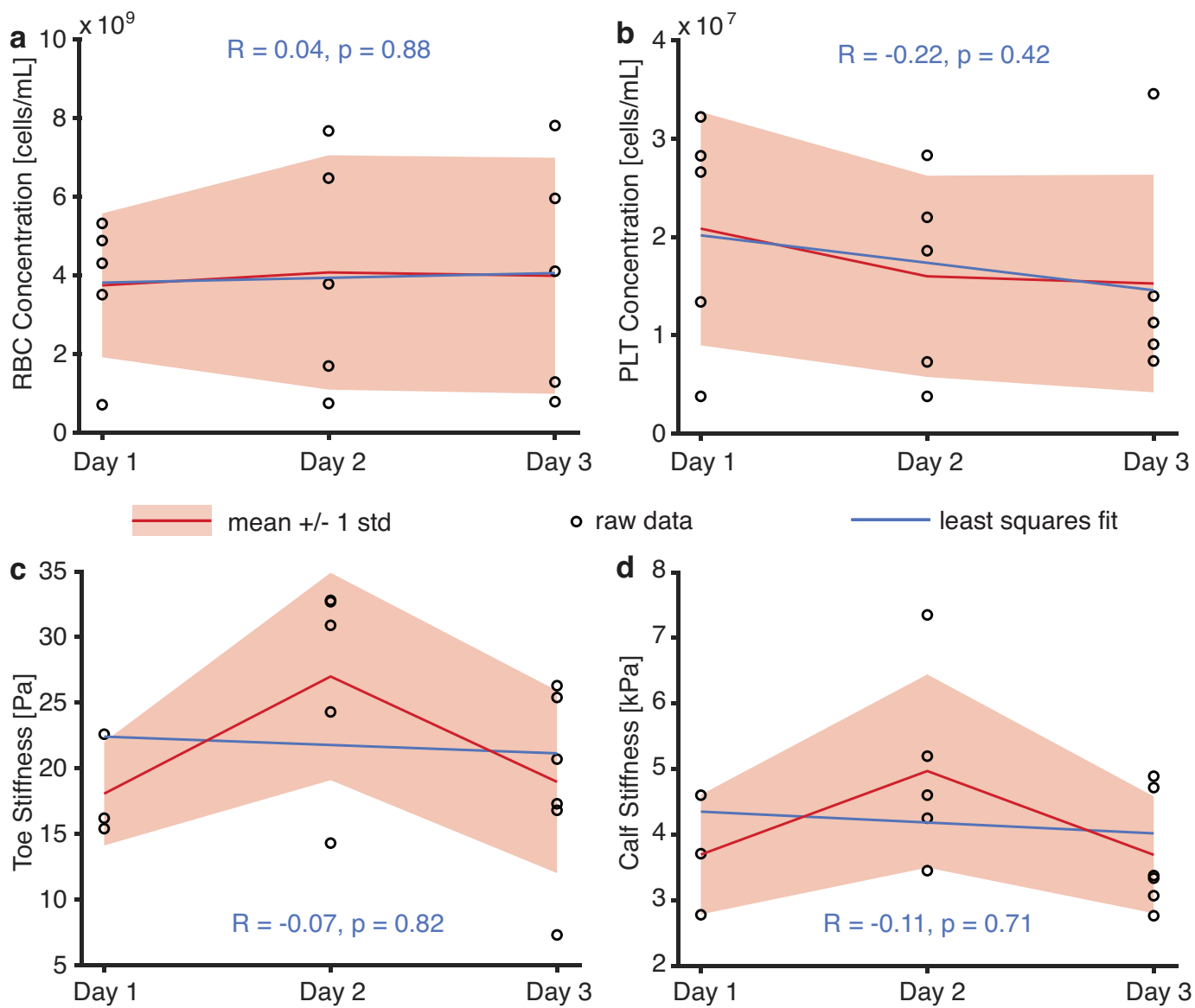

Figure 7: Cell counts and stiffness of thrombus mimics didn't appear to depend on storage time between 24-72 hours. Manual counts of (a) red blood cells, (b) platelets ( $n=5$ counts per day). (c) Toe-stiffness and (d) calf-stiffness of thrombus mimics coagulated with $20 \mathrm{mM}$ calcium chloride for $60 \mathrm{~min}(\mathrm{n}=3,4,5$ per group, by day, respectively).

sus venous side, pre-mortem versus post-mortem, in-vitro versus in-vivo, etc.). Additionally, thrombus testing methods have varied, employing uniaxial tensile and compressive testing, planar biaxial testing, nanoindendation, small and large angle shear rheometry, and now simple shear (this publication). For a comprehensive review of the thrombus mechanics literature please see Johnson et al. and the works cited therein (Johnson et al., 2017). Interestingly, van Oosten et al. have argued that it is the densely-packed cellular ele- ments in thrombus that may render it non-shear stiffening. Disagreement between their argument and a number of publication demonstrating otherwise have so far not been discussed (to the best of our knowledge). As to our finding that thrombus exhibits a negative Poynting effect: This means that our thrombus mimics pulled on our pin stubs while they were sheared rather than trying to expand them. In contrast, other soft tissues such as brain show the opposite effect (Destrade et al., 2012). This effect has recently been attributed 
bioRxiv preprint doi: https://doi.org/10.1101/2020.07.19.210732; this version posted July 19, 2020. The copyright holder for this preprint (which was not certified by peer review) is the author/funder, who has granted bioRxiv a license to display the preprint in perpetuity. It is made available under aCC-BY-ND 4.0 International license.

Mechanics of a Whole Blood Thrombus Mimic
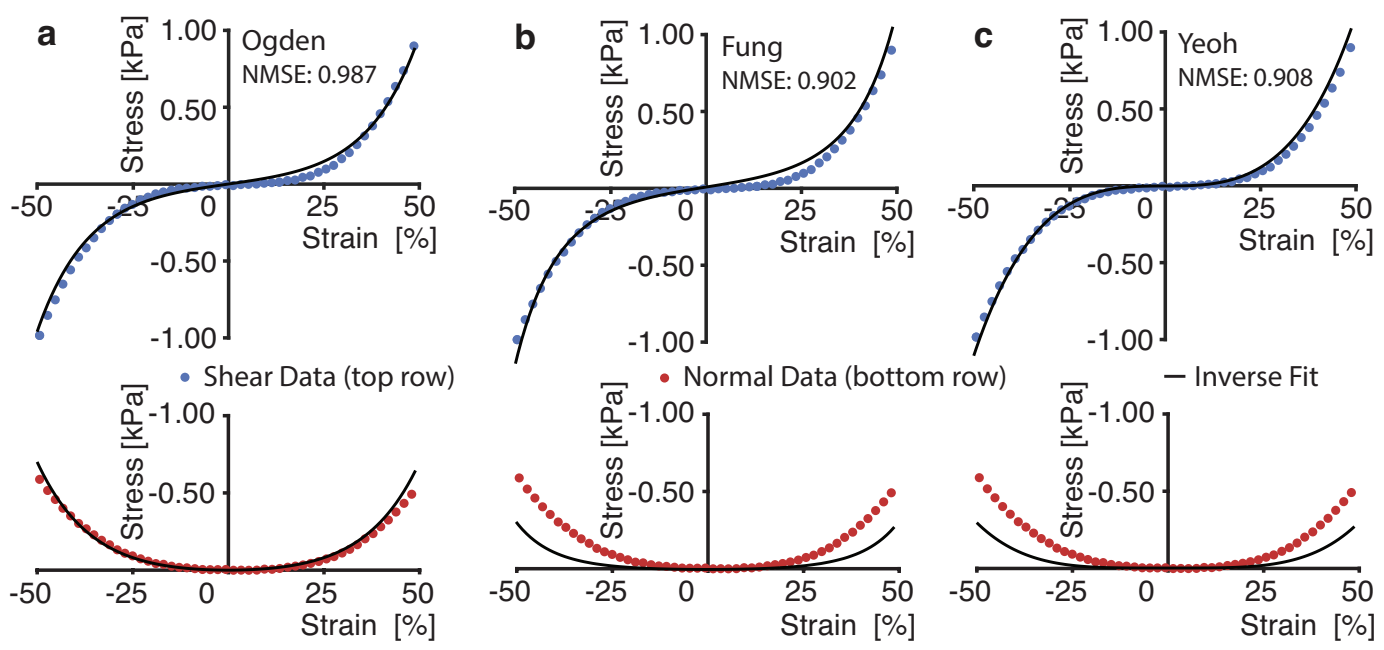

Figure 8: The Ogden model fit the mechanical behavior of our thrombus mimics best. Representative inverse model fits of shear (blue, top) and normal (red, bottom) stress for (a) Ogden, (b) Fung, (c) Yeoh models. Also shown are normalized mean-square error (NMSE) for each fit. This representative thrombus mimic was coagulated with $20 \mathrm{mM}$ calcium chloride for 60 min. Note, a perfect fits yields a NMSE of 1 . Thus, the higher the NMSE the better the fit.

to the strain-stiffening response of the underlying fibrin network (Janmey et al., 2007) and has further been discussed in the context of rubber-theory (Mihai and Goriely, 2011). Additionally, it has been proposed that it is the clot porosity that may give rise to the negative Poynting effect seen in our data (de Cagny et al., 2016). Finally, all soft tissues exhibit viscoelastic behavior as indicated by differences between the loading and unloading curve (i.e., hysteresis). As mentioned above, we chose simple shear as our test modality to minimize viscoelastic effects in our data (Gardiner and Weiss, 2001). However, while the majority of viscoelasticity in thrombus likely arises from its poroelasticity, some unarguable also arises from the solid-phase viscoelasticity of fibrin (Rausch et al., 2009). Future studies may explore the relative contribution between these two sources in a dedicated study.

Quantitatively, we have few studies to compare our data to as there have been no large deformation simple shear experiments on in-vitro thrombus mimics before. However, we can compare our findings to the findings of others as we reduced the constitutive response of our mimics to two scalar metrics, i.e., toe-stiffness and calf-stiffness, which represent the full range of our mimics' stiffness. Specifically, we found toe-stiffness of $\approx 30 \mathrm{~Pa}$ and the calf-stiffness of $\approx 5 \mathrm{kPa}$. These values indicate that thrombus is "ultra-soft" and compare well with findings of others (Riha et al., 1999).

\subsection{Constitutive Modeling}

In our current work we chose to approximate the material behavior of our thrombus mimics as hyperelastic. Theoretically this means that the stress tensor was derived from a scalar function, the strain energy function. Practically, this implies that we ignore viscoelastic phenomena such as hysteresis, strain-rate dependence, stress-relaxation, etc. We chose this approach as it is commonly used as a first approximation to the mechanical behavior of soft tissues, while providing an appropriate framework for modeling materials that undergo very large deformations. As we planned on modeling our material as hyperelastic, we chose a quasistatic strain rate that renders the time-dependent phenomena negligible (i.e., we allow the material to equilibriate while it deforms). In future studies, we will investigate the timeand rate-dependent behavior of our thrombus mimics across various strain-rates and relaxation times. Of the three models, the Ogden model captured our mimics' material behavior most accurately. It should also be noted that the Ogden model with only two parameters exceeded the quality of the Yeoh model with three parameters, further highlighting its ability to capture our mimics' behavior. Thus, we recommend this model when using our data and suggest that other studies of the mechanical behavior of whole blood samples consider the Ogden model as well.

\subsection{Mimic Composition and Blood Storage Time}

We found that the mechanics of our thrombus mimics were relatively insensitive to coagulation conditions and blood storage time. To test the latter, we counted platelets and red blood cells across a period of 3 days and determined their concentrations. Those tests found little change in live cell concentration. Quantitatively, our numbers agree with those reported in the literature for bovine blood (Roland et al., 2014). Anecdotally, our findings also agree with statements by Chernysh et al., who state in their work that "RBCs are typically stored for up to 42 days, and we know from other studies that levels of ATP, 2,3-DPG fall very slowly over many days, and structural changes are also slow. On the other hand, platelets are only stored for a maximum of 5 days." (Chernysh et al., 2020). Additionally, we investigated whether the toe-stiffness and/or calf-stiffness significantly varied over time and found no significant correlation there either. Thus, in agreement with Chernysh et al., we suggest that the mechanics of thrombus mimics like ours is stable 
bioRxiv preprint doi: https://doi.org/10.1101/2020.07.19.210732; this version posted July 19, 2020. The copyright holder for this preprint (which was not certified by peer review) is the author/funder, who has granted bioRxiv a license to display the preprint in perpetuity. It is made available under aCC-BY-ND 4.0 International license.

Mechanics of a Whole Blood Thrombus Mimic

between days 1 and 3 of storage.

\subsection{Future Directions}

This was the first step in our attempt of establishing an invitro thrombus mimic toward understanding thrombus mechanics. While we successfully generated and mechanically tested our thrombus mimics, explored their sensitivity to coagulation conditions, and identified their constitutive behavior, there is much work to be done. In the future, we will first compare our in-vitro thrombus mimics based on bovine blood to samples generated from human blood to ensure clinical relevance of our findings. Secondly, we will begin to generate mimics that resemble thrombi of various degrees of maturation. To this end, we will vary the mimics' composition as well as co-polymerize collagen during clot generation. For validation of this approach, we will compare the histomechanics of our in-vitro thrombus mimics to samples excised from patients.

\subsection{Limitations}

Naturally, this work shows some limitations. First and foremost, we performed all studies on bovine blood, not human blood. Thus, care must be taken before extrapolating our findings to human thrombus. In terms of cell viability, our current manual method for tracking the number of live red blood cells and platelets, albeit standard and historically proven, is subject to high variability and thus uncertainty. Most importantly, our mimics were not formed in-vivo. While in-vitro formation ensures consistency, homogeneity, and conformation with geometric requirements, it produces "unnatural" thrombi. This implies, among other differences, that these mimics have not been invaded by inflammatory or synthetic cell species (Lee et al., 2015), demonstrate no neovascularization (Wakefield et al., 1999) or fissures or sinuous cavity formations (Fineschi et al., 2009), no fibrinolysis has occured (Longstaff and Kolev, 2015), no collagen has been deposited (Wakefield et al., 2008), no Lines of Zahn are apparent (Lee et al., 2012), and no shear flowinduced topical anisotropy is present (Campbell et al., 2010).

\section{Conclusion}

We developed a robust protocol to generate regularlyshaped, homogeneous thrombus mimics that lend themselves to simple shear testing under large deformation. Our data demonstrate that those mimics exhibited shear-stiffening, a negative Poynting effect, and hysteresis and that the material properties were insensitive to coagulation conditions and storage conditions (within the first three days). Additionally, we found that the Ogden material model fits these mechanical data excellently. Future studies will focus on comparing our findings to those of in-vivo thrombi and on extending our mimics to also represent maturing thrombus.

\section{Acknowledgements}

\section{Disclosures}

None of the authors have conflicts of interest to disclose.

\section{References}

Ashrani, A.A., Heit, J.A., 2009. Incidence and cost burden of postthrombotic syndrome. Journal of thrombosis and thrombolysis 28 , 465-76. URL: http://www.ncbi.nlm.nih.gov/pubmed/19224134http: //www. pubmedcentral.nih.gov/articlerender.fcgi?artid=PMC4761436, doi:10.1007/s11239-009-0309-3.

Basmadjian, D., 1989. Embolization: Critical thrombus height, shear rates, and pulsatility. Patency of blood vessels. Journal of Biomedical Materials Research 23, 1315-1326. doi:10.1002/jbm. 820231108.

Beckman, M.G., Hooper, W.C., Critchley, S.E., Ortel, T.L., 2010. Venous thromboembolism: a public health concern. American journal of preventive medicine 38, S495-S501.

Brown, A.E.X., Litvinov, R.I., Discher, D.E., Purohit, P.K., Weisel, J.W., 2009. Multiscale mechanics of fibrin polymer: gel stretching with protein unfolding and loss of water. Science (New York, N.Y.) 325, 741-4. URL: http://www. ncbi.nlm.nih. gov/pubmed/19661428http: //www. pubmedcentral.nih.gov/articlerender.fcgi?artid=PMC2846107, doi:10.1126/science. 1172484 .

de Cagny, H.C., Vos, B.E., Vahabi, M., Kurniawan, N.A., Doi, M., Koenderink, G.H., MacKintosh, F.C., Bonn, D., 2016. Porosity governs normal stresses in polymer gels. Physical review letters 117, 217802.

Campbell, R.A., Aleman, M.M., Gray, L.D., Falvo, M.R., Wolberg, A.S., 2010. Flow profoundly influences fibrin network structure: implications for fibrin formation and clot stability in haemostasis. Thrombosis and haemostasis 104, 1281-1284.

Chernysh, I.N., Spiewak, R., Cambor, C.L., Purohit, P.K., Weisel, J.W., 2020. Structure, mechanical properties, and modeling of cyclically compressed pulmonary emboli. Journal of the Mechanical Behavior of Biomedical Materials 105, 103699. URL: https://doi.org/10.1016/j. jmbbm. 2020.103699, doi:10.1016/j. jmbbm. 2020.103699.

Cushman, M., 2007. Epidemiology and risk factors for venous thrombosis, in: Seminars in hematology, Elsevier. pp. 62-69.

Demiray, H., 1972. A note on the elasticity of soft biological tissues. Journal of biomechanics 5, 309-311.

Destrade, M., Murphy, J.G., Saccomandi, G., 2012. Simple shear is not so simple. International Journal of Non-Linear Mechanics 47, 210-214. doi:10.1016/j.ijnonlinmec. 2011.05.008, arXiv: 1302.2411.

Dewyer, N.A., Sood, V., Lynch, E.M., Luke, C.E., Upchurch, G.R., Wakefield, T.W., Kunkel, S., Henke, P.K., Henke, P.K., 2007. Plasmin inhibition increases MMP-9 activity and decreases vein wall stiffness during venous thrombosis resolution. The Journal of surgical research 142, 357-63. URL: http://www.ncbi.nlm. nih.gov/pubmed/17574586http: //www. pubmedcentral.nih.gov/articlerender. fcgi?artid=PMC2080676, doi:10.1016/j.jss.2007.03.064.

Di Martino, E., Mantero, S., Inzoli, F., Melissano, G., Astore, D., Chiesa, R., Fumero, R., 1998. Biomechanics of abdominal aortic aneurysm in the presence of endoluminal thrombus: experimental characterisation and structural static computational analysis. European Journal of Vascular and Endovascular Surgery 15, 290-299.

Fineschi, V., Turillazzi, E., Neri, M., Pomara, C., Riezzo, I., 2009. Histological age determination of venous thrombosis: a neglected forensic task in fatal pulmonary thrombo-embolism. Forensic science international $186,22-28$.

Fleissner, F., Bonn, M., Parekh, S.H., 2016. Microscale spatial heterogeneity of protein structural transitions in fibrin matrices. Science advances 2, e 1501778.

Fung, Y., 1967. Elasticity of soft tissues in simple elongation. American Journal of Physiology-Legacy Content 213, 1532-1544.

Gardiner, J.C., Weiss, J.A., 2001. Simple shear testing of parallel-fibered planar soft tissues. J. Biomech. Eng. 123, 170-175.

Gasser, T.C., Görgülü, G., Folkesson, M., Swedenborg, J., 2008. Failure properties of intraluminal thrombus in abdominal aortic aneurysm under static and pulsating mechanical loads. Journal of vascular surgery 48 , 179-188.

Geest, J.P.V., Sacks, M.S., Vorp, D.A., 2006. A planar biaxial constitutive relation for the luminal layer of intra-luminal thrombus in abdominal aortic aneurysms. Journal of biomechanics 39, 2347-2354.

Gersh, K.C., Nagaswami, C., Weisel, J.W., 2009. Fibrin net- 
bioRxiv preprint doi: https://doi.org/10.1101/2020.07.19.210732; this version posted July 19, 2020. The copyright holder for this preprint (which was not certified by peer review) is the author/funder, who has granted bioRxiv a license to display the preprint in perpetuity. It is made available under aCC-BY-ND 4.0 International license.

\section{Mechanics of a Whole Blood Thrombus Mimic}

work structure and clot mechanical properties are altered by incorporation of erythrocytes. Thrombosis and Haemostasis 102, 1169-1175. URL: http://www. thieme-connect.de/DoI/DOI?10.1160/ TH09-03-0199, doi:10.1160/TH09-03-0199.

Holzapfel, A.G., 2000. Nonlinear solid mechanics II. John Wiley \& Sons, Inc.

Holzapfel, G.A., Gasser, T.C., Ogden, R.W., 2000. A new constitutive framework for arterial wall mechanics and a comparative study of material models. Journal of elasticity and the physical science of solids 61 , $1-48$.

Horgan, C.O., Murphy, J.G., 2011. Simple shearing of soft biological tissues. Proceedings of the Royal Society A: Mathematical, Physical and Engineering Sciences 467, 760-777.

Janmey, P.A., McCormick, M.E., Rammensee, S., Leight, J.L., Georges, P.C., MacKintosh, F.C., 2007. Negative normal stress in semiflexible biopolymer gels. Nature Materials 6, 48-51. URL: http://www. nature. com/articles/nmat1810, doi:10.1038/nmat1810.

Johnson, S., Duffy, S., Gunning, G., Gilvarry, M., McGarry, J.P., McHugh, P.E., 2017. Review of Mechanical Testing and Modelling of Thrombus Material for Vascular Implant and Device Design. Annals of Biomedical Engineering 45, 2494-2508. doi:10.1007/s10439-017-1906-5.

Kearon, C., 2003. Natural history of venous thromboembolism. Circulation $107, \mathrm{I}-22$.

Kim, O.V., Litvinov, R.I., Alber, M.S., Weisel, J.W., 2017. Quantitative structural mechanobiology of platelet-driven blood clot contraction. Nature communications $8,1-10$.

van Langevelde, K., Srámek, A., Vincken, P.W.J., van Rooden, J.K., Rosendaal, F.R., Cannegieter, S.C., 2013. Finding the origin of pulmonary emboli with a total-body magnetic resonance direct thrombus imaging technique. Haematologica 98, 30915. URL: http://www.ncbi.nlm.nih.gov/pubmed/22801962http: //www. pubmedcentral. nih. gov/articlerender. fcgi?artid=PMC3561441, doi:10.3324/haematol.2012.069195.

Lee, R., Adlam, D., Clelland, C.A., Channon, K.M., 2012. Lines of zahn in coronary artery thrombus. European heart journal 33, 1039-1039.

Lee, Y.U., Lee, A., Humphrey, J., Rausch, M., 2015. Histological and biomechanical changes in a mouse model of venous thrombus remodeling. Biorheology 52, 235-245.

Liu, W., Jawerth, L.M., Sparks, E.A., Falvo, M.R., Hantgan, R.R., Superfine, R., Lord, S.T., Guthold, M., 2006. Fibrin fibers have extraordinary extensibility and elasticity. Science (New York, N.Y.) 313, 634. URL: http://www. ncbi.nlm.nih.gov/pubmed/16888133http: //www. pubmedcentral.nih. gov/articlerender. fcgi?artid=PMC1950267, doi:10.1126/science. 1127317.

Longstaff, C., Kolev, K., 2015. Basic mechanisms and regulation of fibrinolysis. Journal of Thrombosis and Haemostasis 13, S98-S105.

Maas, S.A., Ellis, B.J., Ateshian, G.A., Weiss, J.A., 2012. Febio: finite elements for biomechanics. Journal of biomechanical engineering 134.

Meador, W.D., Mathur, M., Sugerman, G.P., Jazwiec, T., Malinowski, M., Bersi, M.R., Timek, T.A., Rausch, M.K., 2020a. A detailed mechanical and microstructural analysis of ovine tricuspid valve leaflets. Acta biomaterialia 102, 100-113.

Meador, W.D., Sugerman, G.P., Story, H.M., Seifert, A.W., Bersi, M.R., Tepole, A.B., Rausch, M.K., 2020b. The regional-dependent biaxial behavior of young and aged mouse skin: A detailed histomechanical characterization, residual strain analysis, and constitutive model. Acta Biomaterialia 101, 403-413.

Mihai, L.A., Goriely, A., 2011. Positive or negative poynting effect? the role of adscititious inequalities in hyperelastic materials. Proceedings of the Royal Society A: Mathematical, Physical and Engineering Sciences 467, 3633-3646.

Nguyen, K.P., McGilvray, K.C., Puttlitz, C.M., Mukhopadhyay, S., Chabasse, C., Sarkar, R., 2015. Matrix Metalloproteinase 9 (MMP-9) Regulates Vein Wall Biomechanics in Murine Thrombus Resolution. PloS one 10, e0139145. URL: $\quad$ http://www.ncbi.nlm.nih.gov/pubmed/26406902http://www. pubmedcentral.nih.gov/articlerender. fcgi?artid=PMC4583298, doi:10.1371/journal pone. 0139145 .
Ogden, R.W., 1973. Large Deformation Isotropic Elasticity - on the Correlation of Theory and Experiment for Incompressible Rubberlike Solids. Rubber Chemistry and Technology 46, 398-416. doi:10.5254/1.3542910.

van Oosten, A.S., Chen, X., Chin, L., Cruz, K., Patteson, A.E., Pogoda, K., Shenoy, V.B., Janmey, P.A., 2019. Emergence of tissue-like mechanics from fibrous networks confined by close-packed cells. Nature 573, 96101.

Piechocka, I.K., Bacabac, R.G., Potters, M., MacKintosh, F.C., Koenderink, G.H., 2010. Structural Hierarchy Governs Fibrin Gel Mechanics. Biophysical Journal 98, 2281-2289. URL: https://www. sciencedirect. com/science/article/pii/s0006349510002055?via\{\%\}3Dihub, doi:10.1016/ J.BPJ. 2010.01.040.

Rausch, M., Reese, S., Maas, S., Weiss, J., 2009. Can poroelasticity predict the cyclic tensile viscoelastic behavior of ligament, in: Proceedings of the 55th Annual Meeting of the Orthopaedic Research Society.

Rausch, M.K., Humphrey, J.D., 2016. A microstructurally inspired damage model for early venous thrombus. Journal of the mechanical behavior of biomedical materials 55, 12-20.

Rausch, M.K., Humphrey, J.D., 2017. A computational model of the biochemomechanics of an evolving occlusive thrombus. Journal of Elasticity $129,125-144$.

Riha, P., Wang, X., Liao, R., Stoltz, J.R., 1999. Elasticity and fracture strain of whole blood clots. Clinical Hemorheology and Microcirculation 21, 45-49.

Roessler, F.C., Teichert, A., Ohlrich, M., Marxsen, J.H., Stellmacher, F., Tanislav, C., Seidel, G., 2014. Development of a new clot formation protocol for standardized in vitro investigations of sonothrombolysis. Journal of Neuroscience Methods 237, 26-32. URL: http://www.ncbi.nlm.nih.gov/pubmed/25193162https:// linkinghub.elsevier.com/retrieve/pii/S0165027014003173, doi:10.1016/ j. jneumeth. 2014.08.025.

Roland, L., Drillich, M., Iwersen, M., 2014. Hematology as a diagnostic tool in bovine medicine. Journal of Veterinary Diagnostic Investigation 26, 592-598. doi:10.1177/1040638714546490.

Schmid, H., O'Callaghan, P., Nash, M.P., Lin, W., LeGrice, I.J., Smaill, B.H., Young, A.A., Hunter, P.J., 2008. Myocardial material parameter estimation: A non-homogeneous finite element study from simple shear tests. Biomechanics and Modeling in Mechanobiology 7, 161173. URL: http://www. cmiss. org, doi:10.1007/s10237-007-0083-0.

Suh, J.K., DiSilvestro, M., 1999. Biphasic poroviscoelastic behavior of hydrated biological soft tissue. Journal of Applied Mechanics 66, 528535 .

Teng, Z., Feng, J., Zhang, Y., Huang, Y., Sutcliffe, M.P., Brown, A.J., Jing, Z., Gillard, J.H., Lu, Q., 2015. Layer-and direction-specific material properties, extreme extensibility and ultimate material strength of human abdominal aorta and aneurysm: a uniaxial extension study. Annals of biomedical engineering 43, 2745-2759.

Tutwiler, V., Mukhitov, A.R., Peshkova, A.D., Le Minh, G., Khismatullin, R., Vicksman, J., Nagaswami, C., Litvinov, R.I., Weisel, J.W., 2018. Shape changes of erythrocytes during blood clot contraction and the structure of polyhedrocytes. Scientific reports 8, 1-14.

Wakefield, T.W., Linn, M.J., Henke, P.K., Kadell, A.M., Wilke, C.A., Wrobleski, S.K., Sarkar, M., Burdick, M.D., Myers, D.D., Strieter, R.M., 1999. Neovascularization during venous thrombosis organization: a preliminary study. Journal of vascular surgery 30, 885-893.

Wakefield, T.W., Myers, D.D., Henke, P.K., 2008. Mechanisms of venous thrombosis and resolution. Arteriosclerosis, thrombosis, and vascular biology 28, 387-391.

Yeoh, O.H., 1993. Some forms of the strain energy function for rubber. Rubber Chemistry and technology 66, 754-771. 
bioRxiv preprint doi: https://doi.org/10.1101/2020.07.19.210732; this version posted July 19, 2020. The copyright holder for this preprint (which was not certified by peer review) is the author/funder, who has granted bioRxiv a license to display the preprint in perpetuity. It is made available under aCC-BY-ND 4.0 International license.

Mechanics of a Whole Blood Thrombus Mimic

Table 1

Estimated material parameters of all 3 constitutive models, for every sample tested, with corresponding normalized mean squared errors (NMSE) where A: Concentration of calcium chloride [mM], B: Coagulation time [min], and C: Replicate Number. Note, a perfect fits yields a NMSE of 1 . Thus, the higher the NMSE the better the fit.

\begin{tabular}{|c|c|c|c|c|c|c|c|c|c|c|c|c|}
\hline \multirow{2}{*}{$A$} & \multirow{2}{*}{ B } & \multirow{2}{*}{$\mathrm{C}$} & \multicolumn{2}{|c|}{ Ogden Parameters } & \multicolumn{2}{|c|}{ Fung Parameters } & \multicolumn{3}{|c|}{ Yeoh Parameters } & \multicolumn{3}{|c|}{ NMSE } \\
\hline & & & $c_{1}(\mathrm{~Pa})$ & $c_{2}(-)$ & $c_{1}(\mathrm{~Pa})$ & $c_{2}(-)$ & $c_{1}(\mathrm{~Pa})$ & $c_{2}(\mathrm{~Pa})$ & $c_{3}(\mathrm{~Pa})$ & Ogden & Fung & Yeoh \\
\hline \multirow{9}{*}{10} & \multirow{3}{*}{60} & 1 & 584.28 & 16.35 & 329.21 & 8.54 & 0.25 & 1655.26 & 2296.56 & 0.985 & 0.893 & 0.899 \\
\hline & & 2 & 851.56 & 15.29 & 453.32 & 8.00 & 12.79 & 2324.01 & 1751.37 & 0.985 & 0.910 & 0.915 \\
\hline & & 3 & 768.91 & 15.65 & 412.01 & 8.29 & 1.60 & 2126.79 & 2189.50 & 0.979 & 0.919 & 0.924 \\
\hline & \multirow{3}{*}{90} & 1 & 622.05 & 16.22 & 355.91 & 8.35 & 18.84 & 1613.72 & 2642.16 & 0.984 & 0.909 & 0.914 \\
\hline & & 2 & 772.41 & 15.91 & 419.93 & 8.41 & 0.01 & 2189.79 & 2388.77 & 0.983 & 0.911 & 0.917 \\
\hline & & 3 & 819.98 & 15.55 & 434.81 & 8.27 & 21.72 & 2113.08 & 2493.28 & 0.984 & 0.918 & 0.923 \\
\hline & \multirow{3}{*}{120} & 1 & 530.39 & 16.32 & 300.75 & 8.47 & 21.69 & 1381.59 & 2209.34 & 0.989 & 0.890 & 0.895 \\
\hline & & 2 & 611.11 & 15.99 & 305.47 & 9.14 & 8.97 & 1409.62 & 3390.48 & 0.956 & 0.955 & 0.960 \\
\hline & & 3 & 961.40 & 15.35 & 526.70 & 7.83 & 7.06 & 2741.11 & 1672.24 & 0.987 & 0.902 & 0.908 \\
\hline \multirow{9}{*}{20} & \multirow{3}{*}{60} & 1 & 560.82 & 16.38 & 298.93 & 9.01 & 1.54 & 1456.56 & 2922.19 & 0.972 & 0.931 & 0.937 \\
\hline & & 2 & 837.06 & 15.64 & 431.86 & 8.57 & 0.08 & 2204.81 & 2935.81 & 0.973 & 0.933 & 0.939 \\
\hline & & 3 & 650.69 & 16.26 & 351.59 & 8.81 & 0.13 & 1773.09 & 2873.17 & 0.976 & 0.925 & 0.932 \\
\hline & \multirow{3}{*}{90} & 1 & 777.55 & 15.64 & 412.33 & 8.34 & 0.08 & 2163.39 & 2157.83 & 0.981 & 0.916 & 0.922 \\
\hline & & 2 & 717.81 & 15.46 & 384.11 & 8.10 & 4.12 & 2010.73 & 1579.70 & 0.983 & 0.906 & 0.912 \\
\hline & & 3 & 899.49 & 15.14 & 490.33 & 7.66 & 15.36 & 2536.95 & 1132.92 & 0.990 & 0.889 & 0.895 \\
\hline & \multirow{3}{*}{120} & 1 & 515.83 & 15.15 & 266.30 & 8.13 & 20.92 & 1199.10 & 1655.79 & 0.971 & 0.935 & 0.940 \\
\hline & & 2 & 621.25 & 16.09 & 316.57 & 9.06 & 0.16 & 1555.22 & 3140.16 & 0.965 & 0.944 & 0.950 \\
\hline & & 3 & 847.24 & 15.38 & 458.64 & 7.94 & 11.78 & 2378.30 & 1564.58 & 0.988 & 0.898 & 0.904 \\
\hline \multirow{9}{*}{40} & \multirow{3}{*}{60} & 1 & 747.15 & 15.07 & 381.16 & 8.09 & 2.75 & 1961.91 & 1718.34 & 0.975 & 0.923 & 0.930 \\
\hline & & 2 & 1401.10 & 11.23 & 487.07 & 7.54 & 100.80 & 1775.62 & 2658.05 & 0.927 & 0.988 & 0.991 \\
\hline & & 3 & 890.52 & 14.68 & 446.89 & 7.90 & 2.98 & 2404.48 & 1241.52 & 0.977 & 0.932 & 0.938 \\
\hline & \multirow{3}{*}{90} & 1 & 657.78 & 16.17 & 361.92 & 8.58 & 0.03 & 1837.67 & 2541.12 & 0.981 & 0.914 & 0.921 \\
\hline & & 2 & 799.69 & 13.87 & 374.07 & 7.67 & 30.06 & 1764.43 & 1296.11 & 0.970 & 0.946 & 0.951 \\
\hline & & 3 & 1054.73 & 14.18 & 580.77 & 6.75 & 55.58 & 2742.89 & 0.04 & 0.990 & 0.878 & 0.884 \\
\hline & \multirow{3}{*}{120} & 1 & 593.99 & 15.37 & 319.31 & 8.01 & 8.07 & 1651.90 & 1191.73 & 0.982 & 0.907 & 0.912 \\
\hline & & 2 & 898.52 & 14.22 & 457.24 & 7.38 & 0.10 & 2333.46 & 988.79 & 0.971 & 0.932 & 0.940 \\
\hline & & 3 & 1090.10 & 13.39 & 536.76 & 6.90 & 26.29 & 2695.45 & 0.05 & 0.979 & 0.925 & 0.932 \\
\hline
\end{tabular}

